\title{
SÍNTESE DO ISOBUTILENO E SEU EMPREGO EM REAÇÕES DE ESTERIFICAÇÃO: PROPOSTAS DE AULAS PRÁTICAS DE QUÍMICA ORGÂNICA PARA A GRADUAÇÃ̃o
}

Silvio Cunha*, Luciano M. Lião, Ricardo R. Bonfim, Rodrigo M. Bastos, Ana Paula M. Monteiro e Kelly S. Alencar

Instituto de Química, Universidade Federal de Goiás, CP 131, 74001-970 Goiânia - GO

Recebido em 7/6/02; aceito em 12/8/02

\begin{abstract}
SYNTHESIS AND ESTERIFICATION REACTIONS OF ISOBUTYLENE: AN UNDERGRATUATE ORGANIC CHEMISTRY EXPERIMENT. An experiment for the synthesis of isobutylene from tert-butanol dehydratation using oxalic acid as catalyst, followed by preparations of tert-butyl benzoate and tert-butyl cinnamate is described. The synthesis are simple, requiring two periods of 4 hours and are suitable for undergraduate organic chemistry experimental courses.
\end{abstract}

Keywords: chemical education; isobutylene; tert-butyl benzoate; tert-butyl cinnamate.

Nos cursos de química orgânica experimental da graduação o aluno é introduzido às técnicas básicas de laboratório, bem como à síntese de moléculas orgânicas simples, mediante a interconversão de grupos funcionais e/ou a formação de ligação carbono-carbono e carbono-heteroátomo. Durante quase todo o treinamento laboratorial em química orgânica o graduando manipula substâncias nos estados líquido e sólido. O contato com substâncias gasosas limita-se, em geral, à observação do desprendimento de gás numa reação, na maioria das vezes de natureza inorgânica. Dessa forma, o aluno tende a incorporar a noção de que substâncias orgânicas gasosas não são muito utilizadas em síntese orgânica, a não ser como combustíveis no bico de Bunsen. Esta situação está em franco contraste com os inúmeros exemplos de reações recursivamente empregados nos cursos teóricos, em que o substrato orgânico encontra-se no estado gasoso no ambiente do laboratório (como os hidrocarbonetos e os haloalcanos de massa molecular pequena), e também com a síntese orgânica industrial, onde vários gases orgânicos são empregados ${ }^{1}$.

Motivados por estes fatos, por relatos recentes de inovações no ensino de química orgânica experimental ${ }^{2}$, e pela inexistência, nos livros textos tradicionalmente adotados ${ }^{3}$, de práticas envolvendo gases orgânicos como reagentes, decidimos elaborar um experimento para o curso de graduação da nossa instituição, onde o gás isobutileno (metil-propeno) foi sintetizado, submetido a teste químico de caracterização funcional e empregado em reações de esterificação, englobando mecanismos de reações de eliminação e de adição.

Estratégia das aulas: o experimento compreende duas aulas de $4 \mathrm{~h}$ e aborda uma diversidade de técnicas de laboratório bem como de métodos de caracterização do produto, de acordo com o Quadro 1. Na primeira aula, o gás isobutileno é gerado e inicia-se uma reação específica (vide infra), cujo tratamento, isolamento e caracterização do produto é realizado na aula semanal seguinte. Dependendo da disponibilidade dos ácidos carboxílicos, metade da turma pode preparar o benzoato de terc-butila e a outra metade o cinamato de terc-butila.

Síntese do gás isobutileno: o isobutileno é preparado através da desidratação do terc-butanol utilizando a aparelhagem apresentada na Figura 1. Emprega-se o ácido oxálico como catalisador desta reação, e o mesmo é facilmente recuperado por meio de uma recristalização em água. Outro diferencial é o fato deste promotor ser um ácido orgânico, não gerando, assim, resíduo inorgânico como

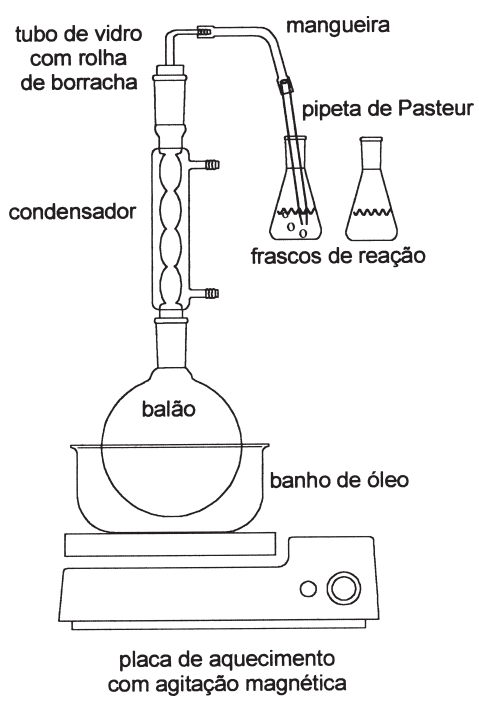

Figura 1. Equipamento para geração do gás isobutileno

Quadro 1

\begin{tabular}{|c|c|c|c|c|c|}
\hline Aula & Experimento & Tipo de reação & Tipo de mecanismo & Técnicas experimentais & Técnicas de identificação \\
\hline 1 e 2 & $\begin{array}{l}\text { Síntese do benzoato } \\
\text { ou do cinamato } \\
\text { de terc-butila }\end{array}$ & $\begin{array}{l}\text { Desidratação } \\
\text { Esterificação }\end{array}$ & $\begin{array}{l}\text { Eliminação } \\
\text { Adição }\end{array}$ & $\begin{array}{l}\text { Refluxo } \\
\text { Extração } \\
\text { Recristalização }\end{array}$ & $\begin{array}{l}\text { Análise funcional } \\
\text { Infra-vermelho }\end{array}$ \\
\hline
\end{tabular}

* e-mail: silviodc@ufba.br/endereço atual: Instituto de Química, Universidade Federal da Bahia, Campus de Ondina, 40170-290 Salvador - BA 
descarte, em contraste com os experimentos clássicos descritos nos livros textos, que empregam ácidos minerais, como o $\mathrm{H}_{2} \mathrm{SO}_{4} \mathrm{e} \mathrm{H}_{3} \mathrm{PO}_{4}{ }^{3}$.

Uma vez iniciada a formação do gás isobutileno, percebe-se um fluxo constante de bolhas no frasco de reação onde a pipeta de Pasteur encontra-se submersa. Para certificar que o borbulhamento observado é devido à formação do alceno e não à expansão do ar do interior da aparelhagem, deixa-se, inicialmente, que o borbulhamento se dê num tubo de ensaio contendo 2-3 mL de solução $1 \%$ de $\mathrm{KMnO}_{4}$ (teste de Bayer). Tão logo se observe a mudança da coloração de violeta para castanha, troca-se o tubo de ensaio pelo frasco de reação.

Para garantir o fluxo regular do gás isobutileno na etapa de borbulhamento é necessário aquecer o banho de óleo de forma que a taxa de refluxo seja de 1-2 gotas por segundo $\left(\sim 90^{\circ} \mathrm{C}\right)$, e também manter a solução do ácido oxálico em terc-butanol sob forte agitação magnética. Nestas condições é desnecessário o uso de um frasco de segurança ("trap") entre o condensador e o frasco de reação. Ao contrário, a presença do frasco de segurança prolonga excessivamente o início e a velocidade do borbulhamento. Se porventura ocorrer extinção do borbulhamento regular e inversão de pressão, isto é convenientemente contornado removendo-se rapidamente a pipeta de Pasteur do seio da solução, deixando o líquido contido na pipeta retornar para o frasco de reação (a pipeta deve medir não menos que $15 \mathrm{~cm}$, e não se deve deixar o líquido do frasco de reação subir mais que um terço do comprimento da mesma). O borbulhamento é, então, reiniciado. Vale notar que, das várias vezes que o sistema de geração do isobutileno foi empregado, apenas numa única foi preciso lançar mão deste artifício.

O isobutileno é considerado não tóxico ${ }^{5,6}$ e seu cheiro é bem menos penetrante e irritante que o do cicloexeno (que é o alceno classicamente sintetizado para exemplificar a reação de eliminação envolvendo álcoois ${ }^{3}$ ) sendo, portanto, uma alternativa mais agradável de procedimento de síntese de alcenos por meio da desidratação do álcool. Todavia, como se trata de um hidrocarboneto gasoso, devese evitar chama e reforçar a proibição de não fumar no laboratório.

Reação de esterificação: o ácido benzóico e o cinâmico são convertidos no benzoato e cinamato de terc-butila em 52 e $55 \%$ de rendimento, respectivamente, através do borbulhamento do isobutileno numa solução dos ácidos carboxílicos em diclorometano contendo $\mathrm{H}_{2} \mathrm{SO}_{4}$ catalítico (Esquema 1). Estas reações exemplificam o comportamento nucleofílico do ácido carboxílico, diferindo do comportamento eletrofílico destes nas esterificações de Fischer descritas nos livros textos de química orgânica experimental ${ }^{3}$. Adicionalmente, as sínteses dos ésteres aqui apresentadas envolvem a adição do nucleófilo ácido carboxílico à dupla ligação, catalisada por ácido. A comparação dos espectros na região do infra-vermelho dos reagentes e dos produtos (Figura 2) permite avaliar as mudanças estruturais.

\section{CONCLUSÃO}

O experimento proposto, inexistente nos livros textos destinados à graduação, contempla o treinamento do graduando em diversas técnicas de laboratório, bem como na síntese, manuseio e reatividade de substância orgânica gasosa, e envolve os mecanismos iônicos de eliminação e adição. Entretanto, não se limita ao mero treinamento laboratorial pois incorpora elementos que proporcionam: a) inter-relação com aspectos teóricos e também com a síntese orgânica industrial, onde gases orgânicos são usados como reagentes; b) discussão da estabilidade de carbocátions; c) reutilização do catalisador da desidratação, gerando menor quantidade de resíduo, introduzindo a temática de impacto ambiental.

\section{PROCEDIMENTO EXPERIMENTAL}

Geração do gás isobutileno: num balão de fundo redondo de $100 \mathrm{~mL}$ com barra magnética coloque $15 \mathrm{~g}$ de ácido oxálico diidratado e $40 \mathrm{~mL}$ de terc-butanol. Conecte um condensador de refluxo e adapte uma rolha de borracha com tubo de vidro conectado a uma mangueira contendo uma pipeta de Pasteur de aproximadamente $15 \mathrm{~cm}$ na outra extremidade, de acordo com a Figura 1. Aqueça o balão em banho de óleo $\left(\sim 90^{\circ} \mathrm{C}\right)$ mantendo uma taxa de refluxo de 1-2 gotas por segundo, sob forte agitação magnética. Mantenha a ponta da pipeta submersa em 2-3 mL de solução $1 \%$ de $\mathrm{KMnO}_{4}$ até que descore. Remova a pipeta, limpe-a com papel absorvente e a introduza no frasco de reação previamente preparado.

Reação de esterificação: em um erlenmeyer de $125 \mathrm{~mL}$ pese 1,392 g de ácido benzóico (ou 1,630 g de ácido cinâmico), adicione $50 \mathrm{~mL}$ de diclorometano e $0,10 \mathrm{~mL}$ de ácido sulfúrico concentrado, e homogeneize. Introduza a ponta da pipeta de Pasteur do equipamento de geração do isobutileno (Figura 1) e deixe o gás borbulhar nesta solução por $3 \mathrm{~h}$ (o volume aumenta), resfriada em banho de gelo. Tampe o erlenmeyer com uma rolha de borracha e deixe em repouso à temperatura ambiente por 7 dias. Após este período de repouso, resfrie a solução em banho de gelo para, só então, abrir o erlenmeyer. Em seguida, transfira a solução para um funil de separação e extraia sucessivamente com $30 \mathrm{~mL}$ de solução $10 \%$ de $\mathrm{Na}_{2} \mathrm{CO}_{3}$ (duas vezes) e $50 \mathrm{~mL}$ de água destilada. Seque a camada orgânica com $\mathrm{Na}_{2} \mathrm{SO}_{4}$ anidro, filtre e evapore o solvente em um rotaevaporador. Obtém-se o éster na forma de óleo amarelo pouco viscoso suficientemente puro, que é caracterizado por espectroscopia na região do infra-vermelho (Figura 2). O ácido carboxílico que não reagiu pode ser facilmente recuperado da fase aquosa da etapa de extração, acidificando-se o meio.

Recuperação do ácido oxálico por meio da recristalização: deixe o balão contendo o resíduo de ácido oxálico esfriar e, então,

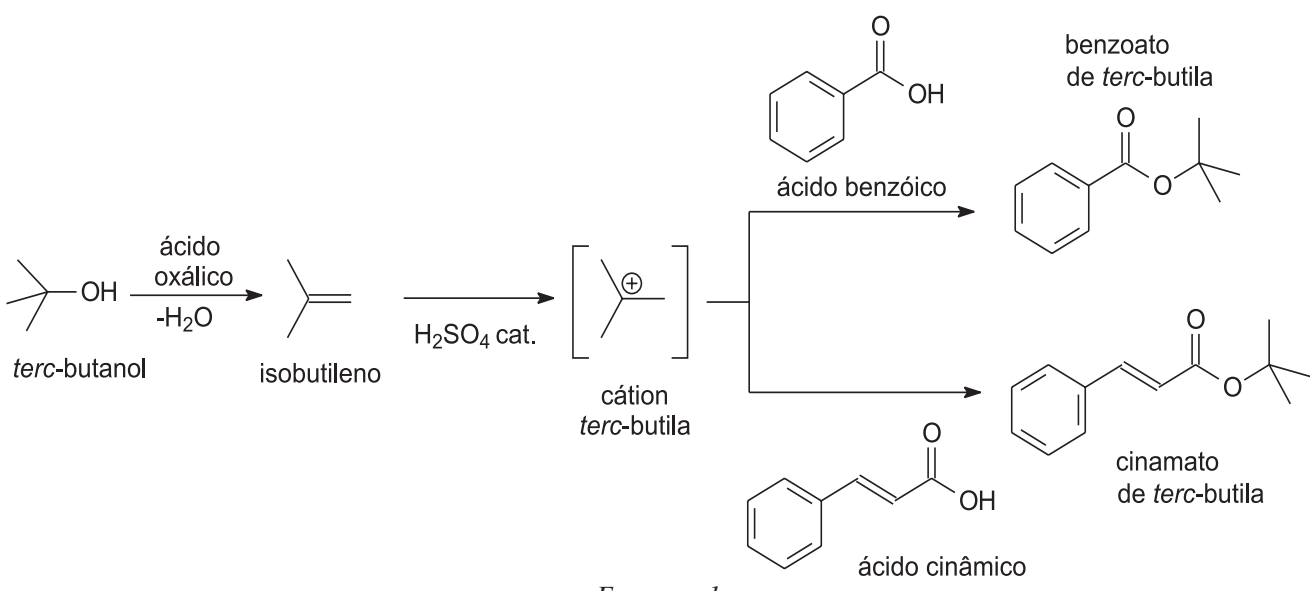



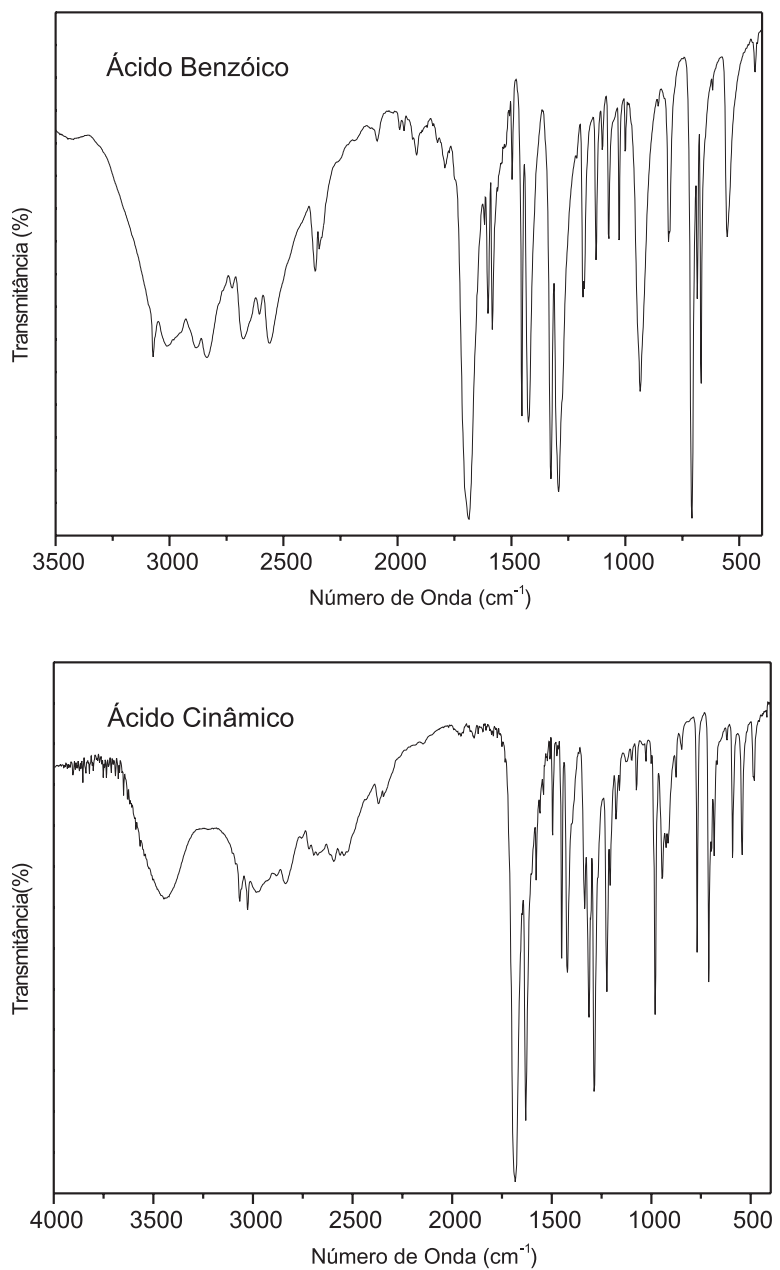

Figura 2. Espectros na região do IV dos ácidos carboxílicos e dos ésteres

fragmente a massa sólida com o auxílio de uma espátula. Adicione $15 \mathrm{~mL}$ de água, agite o balão e verta a mistura para um erlenmeyer de $125 \mathrm{~mL}$. Repita esta operação 2 vezes, somando um volume de $45 \mathrm{~mL}$ de água. Aqueça o erlenmeyer numa chapa de aquecimento até completa solubilização, deixe esfriar para cristalização do ácido. Filtre o sólido em um funil de Buchner e deixe secando ao ar durante uma semana. Recuperam-se $80 \%$ da massa do ácido empregado, que pode ser reutilizado na síntese do isobutileno.

\section{AGRADECIMENTOS}

Os autores agradecem aos alunos dos cursos de química orgânica experimental I (1998) e II (2001) do IQ-UFG, que realizaram os experimentos propostos nas suas versões preliminares, aprimorando-os. Alguns deles se envolveram tanto que se tornaram co-autores deste trabalho (R. R. Bonfim, R. M. Bastos, A. P. M. Monteiro e K. S. Alencar).

\section{REFERÊNCIAS}

1. Weissermel, K.; Arpe, H.-J.; Industrial Organic Chemistry, $2^{\text {nd. }}$. ed., VCH Verlagsgesellschaft mbH: Weinhein, 1993.
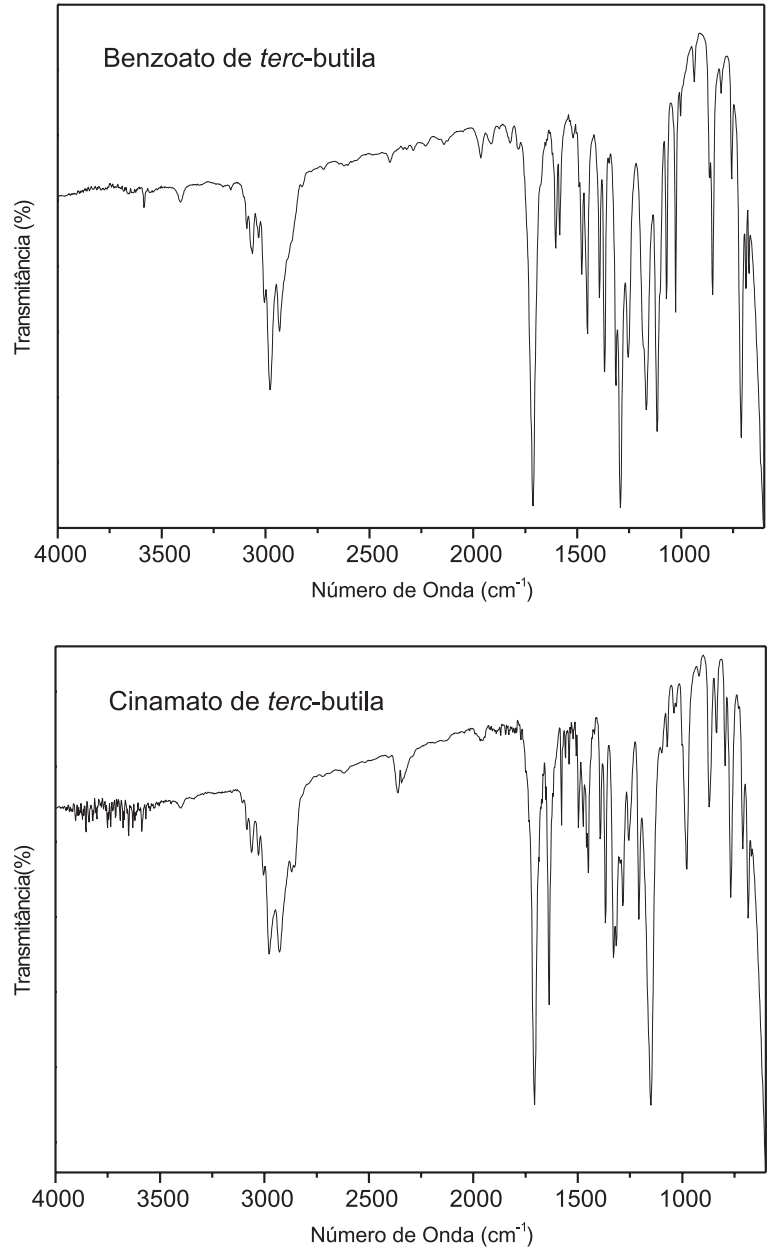

2. Ferreira, V. F.; Silva, F. C.; Perrone, C. C.; Quim. Nova 2001, 24, 905; Imamura, P. M.; Baptistella, L. H. B.; Quim. Nova 2000, 23, 270; Bieber, L. W.; Quim. Nova 1999, 22, 605.

3. Soares, B. G.; Souza, N. A.; Pires, D. X.; Química Orgânica: Teoria e Técnicas de Preparação, Purificação e Identificação de Compostos Orgânicos, Ed. Guanabara S.A.: Rio de Janeiro, 1988; Pavia, D. L.; Lampman, G. M.; Kriz, G. S.; Organic Laboratory Techniques, $2^{\text {nd }}$ ed., Saunders C. Publishing: Phyladelphia, 1982; Furniss, B. S.; Hannaford, A. J.; Smith, P. W. G.; Tactchell, A. R.; Vogel's Textbook of Pratical Organic Chemistry, $5^{\text {th }}$ ed., Longman Scientific \& Technical: Singapore, 1989; Harwood, L. M.; Moody, C. J.; Experimental Organic Chemistry: Principles and Practice, Blackwell Science: Great Britain, 1989; Pavia, D. L.; Lampman, G. M.; Kriz, G. S.; Engel, R. G.; Introduction to Organic Laboratory Techniques: a Small Scale Approach, Saunders College Publishing: Phyladelphia, 1998; Roberts, M. R.; Gilbert, J. C.; Martin, S. F.; Experimental Organic Chemistry: a Miniscale Approach, Saunders College Publishing: Phyladelphia, 1994.

4. Hund, C.; Spence, L. U.; J. Am. Chem. Soc. 1929, 51, 3561.

5. Luxon, S. G.; Hazards in the Chemical Laboratory, $5^{\text {th }}$ ed., Royal Society of Chemistry: Great Britain, 1992.

6. É recomendável que se trabalhe em capela, mas temos usado estes experimentos em turmas de 12-14 alunos trabalhando em duplas, empregando 6-7 montagens simultâneas em bancadas sem capelas, em laboratório com ventilação adequada, e nunca foi registrado incômodo por nenhum dos alunos. 